\title{
BMJ Open Staying ahead of the curve: Navigating changes and maintaining gains in patient safety culture - a mixed- methods study
}

\author{
Maher Abdelraheim Titi (D) , ${ }^{1,2}$ Maram Mohammed Baksh, ${ }^{1}$ Beena Zubairi, ${ }^{1}$ \\ Rawia Ahmad Mustafa Abdalla, ${ }^{1}$ Faisal Abdullah Alsaif, ${ }^{3}$ Yasser S Amer (D) , 1,2,4 \\ Diana Jamal, ${ }^{5}$ Fadi El-Jardali ${ }^{5,6}$
}

To cite: Titi MA, Baksh MM, Zubairi B, et al. Staying ahead of the curve: Navigating changes and maintaining gains in patient safety culture - a mixedmethods study. BMJ Open 2021;11:e044116. doi:10.1136/ bmjopen-2020-044116

- Prepublication history and additional material is published online only. To view, please visit the journal online (http://dx.doi. org/10.1136/bmjopen-2020044116).

Received 25 August 2020 Revised 05 February 2021 Accepted 18 February 2021
Check for updates

(C) Author(s) (or their employer(s)) 2021. Re-use permitted under CC BY-NC. No commercial re-use. See rights and permissions. Published by BMJ.

For numbered affiliations see end of article.

Correspondence to Mr Maher Abdelraheim Titi; mahertiti1980@gmail.com

\section{ABSTRACT}

Objectives This study examines how the results of the Hospital Survey on Patient Safety Culture changed between 2012 and 2019 and identifies organisational factors affecting these changes.

Design The study combined the use of quantitative surveys of staff and qualitative interviews with hospital leadership. Secondary data analysis was performed for previous surveys.

Setting This study was conducted in a tertiary care teaching multisite hospital in Riyadh, Saudi Arabia.

Participants One thousand hospital staff participated in the survey. Thirty-one executive board members and directors and four focus groups of frontliners were qualitatively interviewed.

Primary and secondary outcome measures Twelve safety culture dimensions were assessed to study the patient safety culture as perceived by the healthcare professionals. An additional semi-structured interview was conducted to identify organisational factors, changes, and barriers affecting the patient safety culture. Furthermore, suggestions to improve patient safety were proposed. Results Comparing the results revealed a general positive trend in scores from 2012 to 2019. The areas of strength included teamwork within and across units, organisational learning, managerial support, overall perception of safety and feedback and communication about error. Nonpunitive response to error, staffing and communication and openness consistently remain the lowest-scoring composites. Interview results revealed that organisational changes may have influenced the answers of the participants on some survey composites.

Conclusions Patient safety is a moving target with areas for improvement that are continuously identified. Effective quality improvement initiatives can lead to visible changes in the patient safety culture in a hospital, and consistent leadership commitment and support can maintain these improvements.

\section{INTRODUCTION}

Despite considerable investments in quality healthcare and patient safety over the past decades, patients continue to experience preventable harm, and the current status

\section{Strengths and limitations of this study}

- This is the first study to explore the results of a survey on patient safety culture in four consecutive rounds in Saudi Arabia.

- This study covered almost all categories of healthcare workers, including managers and care providers.

- A mixed-methods design was used to overcome the methodological limitations of the lack of a single tool that could capture the complexities of patient safety culture.

- A lower response rate was observed for the 2019 assessment and compared with previous years; therefore, the results of this study should be interpreted with caution.

- To minimise the occurrence of spurious correlations due to common-method variance in the survey instrument, we have used a mixed-methods design rather than simply applying the survey method alone.

of patient safety around the world remains alarming. ${ }^{1}$ Recent studies have identified adverse events as a serious global issue affecting patient safety. Therefore, identifying and preventing potential harm is a top priority of healthcare organisations, thus enhancing patient outcomes. Evidence suggests that a strong culture of patient safety in a hospital is associated with fewer adverse events and improved patient outcomes. ${ }^{23}$

It is increasingly recognised that healthcare organisations around the world, regardless of economic status, are closely focusing on measuring and enhancing their Patient Safety Culture (PSC). ${ }^{4-6}$ PSC is assessed to provide information to managers and healthcare policymakers; in addition, it can help organisations understand the present state of their PSC and analyse the PSC trends over time. Measuring PSC is important for 
identifying areas of strength and areas needing prioritisation for interventions, evaluating the impact of patient safety initiatives or programmes and tracking changes over time. Furthermore, it improves staff perceptions, develops a better understanding of patient safety, fulfills accreditation or regulatory requirements and conducts internal and external benchmarking. ${ }^{278}$

Measuring PSC is still considered relatively difficult and is well documented in the literature. ${ }^{9}{ }^{10}$ No single tool can sufficiently assess all major components of PSC and provide leaders with clear guidance on how PSC can be effectively improved. ${ }^{11}{ }^{12}$ To explore the complex concept of PSC in healthcare, the mixed-methods approach, by collecting and analysing both quantitative and qualitative data, can be viewed as the most appropriate approach to increase the robustness of the results and gain a deeper understanding of PSC while offsetting the intrinsic weaknesses associated with each approach when used on its own. ${ }^{513}$

Given the clear need for continuous monitoring of PSC and better understanding of how organisational culture changes after multiple interventions and milestones, we used the mixed-methods approach to assess PSC progressively over a period of 8 years. To our knowledge, assessing PSC has not yet been performed at this scale, and this study can provide us insight on the key areas to improve regarding PSC in healthcare organisations and persistent challenges in PSC that are difficult to change rapidly with simple interventions. This study reports on the organisational survey results of 2019 and compares these results with those of three previous assessments at the same multisite facility $\left(2012,{ }^{14} 2015^{4}\right.$ and 2017).

\section{Objectives}

The overall objective of this study is to examine how the results of the Hospital Survey on Patient Safety Culture (HSOPSC) survey changed between 2012 and 2019 and identify organisational factors affecting these changes. Specifically, this study provides an overview of the results of multiple assessments of PSC surveys at a large multisite healthcare facility in Riyadh, Kingdom of Saudi Arabia.

\section{METHODS \\ Design}

In this study, a mixed-methods research design was used to achieve the most comprehensive understanding possible of the research problem. The study combined the use of quantitative surveys and qualitative interviews with hospital staff of different levels to achieve the study objectives. Additionally, we conducted a cross-validation of the results with those of the previous surveys conducted at the same site in $2012,{ }^{14} 2015^{4}$ and 2017.

\section{Setting}

This study was conducted in a tertiary care teaching multisite hospital having a capacity of 1160 beds and approximately 9000 employees. It receives referral patients from all over the country. The hospital has three sites, varying in size and location; site A has 1060 beds and offers free medical services with a wide range of specialties, and site B has 100 beds and offers complementary services to those of site A. Site C offers inpatient and outpatient dental services.

\section{Quantitative component}

The tool (questionnaire)

The tool used was adapted from the HSOPSC developed by the Agency for Healthcare Research and Quality (AHRQ). ${ }^{7}$ The survey is available in English and Arabic. The internal consistency and reliability of the original English version were tested using Cronbach's alpha that ranged between 0.62 and $0.85 .{ }^{15}{ }^{16}$ However, the Arabic version was adapted and used in similar studies in Lebanon, ${ }^{17}$ Saudi Arabia ${ }^{414}$ and Jordan, ${ }^{18}$ and its reliability was measured using Cronbach's coefficient that ranged between 0.45 and $0.81 .{ }^{17}$ The HSOPSC includes 42 items grouped into 12 composites. In addition to the composites, the survey includes two questions asking respondents to provide an overall grade on patient safety and to indicate the number of reported events over the past 12 months.

\section{Participants}

The survey randomly sampled staff targeting $50 \%$ (4500) of clinical and non-clinical employees similar to the previous two assessment rounds by El-Jardali et $a l^{14}$ and Alswat $e t a l^{4}$

\section{Data collection}

Data collection for the 2017 and 2019 surveys were performed in two assessment rounds: from September to November in 2017 and from February to April in 2019. Data collection for the 2012 and 2015 surveys was described in studies by El-Jardali et al $^{14}$ and Alswat et al. ${ }^{4}$

The survey was made available in hard copies and the electronic format for all respondents. The hard-copy surveys were provided in sealed envelopes for respondents who could not access the electronic-format surveys. The first page of the survey included the consent form and an explanation of the purpose of the survey. Employees were not asked to sign the consent form or any other page of the survey; they were asked to return the hard copies of the survey in a sealed envelope.

\section{Data analysis}

Data were analysed using Statistical Package for the Social Sciences, V.25.0 (IBM, Armonk, New York, USA); $\mathrm{p}$ values $>0.05$ were used to denote significance. In addition to answering the study tool, respondents were asked to provide some background demographic information about themselves (age, gender, marital status, profession, educational level, clinical experience, working hours during the week, working area and whether they were trained on patient safety). The composite items were measured using a 5-point Likert response scale of agreement, with the scores ranging from 'strongly disagree' to 
'strongly agree' or frequencies that ranged from 'never' to 'always'. Consequently, the HSOPSC comprised the following two single-item measures:

- The patient safety grade, scored with a 5-point Likert scale ranging from 'excellent' to 'failing'.

- The number of adverse events reported by the respondent during the last year, ranging from "no events' to '21 events or more'.

The results were presented as percentages of the average positive responses (eg, strongly agree/agree and most of the time/always) for each survey item; negatively worded items were reversed when computing their percentages. The per cent positives for each subscale were computed as follows: ((number of positive responses/total number of responses on the item) $\times 100 \%$ ). Missing responses were excluded when displaying the percentages of the responses to the survey items. ${ }^{7}$ Composites that had at least $70 \%$ positive responses were considered areas of strength, whereas those with less scores were considered areas for improvement. Our decision to consider our cut-off point to be $70 \%$ for patient safety areas in need for improvement was based on the results of our previous two PSC surveys conducted in the same facility. Composite scores were calculated by summing the item scores and dividing the sum by the number of items within the composite.

Descriptive statistics such as frequency and percentage were used for data summarisation. Given that the data were not normally distributed for all composites, the independent Kruskal-Wallis $\mathrm{H}$ test was used to determine whether a significant difference exists between survey composites between the 2012, 2015, 2017 and 2019 datasets. The $\chi^{2}$ test was used to determine whether a significant difference exists between the 2012 and 2019 datasets for the questions regarding the number of events and patient safety grade.

\section{Qualitative component \\ Interview tool}

Semi-structured interviews were conducted to probe the topic deeper, make the interviews more conversational and make sure all interview participants, including leaders and frontline staff, were asked the same questions. An interview guide was adapted and modified from previous studies, ${ }^{19-21}$ and an external expert review followed (see online supplemental 1S).

\section{Participants}

We used a purposive sampling technique to recruit interviewees. Thirty-one semi-structured individual interviews were conducted with all executive board members in Medical City, medical directors in each site, directors of the main clinical and supportive services departments and four focus groups of frontliners. Those identified to participate had received an invitation email including all the information about the voluntary nature of participation and an explanation of the entire study phase and a request to record the interviews, which were conducted in a private place (see online supplemental table 1S).

\section{Data collection}

The interviews were scheduled according to the participants' availability. All interviews were conducted in English. Each interview lasted 15-30 $\mathrm{min}$ and was recorded using a digital voice recorder. A research assistant transcribed the recorded data as soon as each interview was completed. The accuracy of the transcriptions was reviewed (and corrected if necessary) by the researchers. In addition, field notes were taken, and the responses and views of the participants were summarised at the end of each interview to ensure that they reflected their views.

Participation was voluntary and the interview tool did not collect any information that could be used to identify the participants. Participant confidentiality was maintained at every stage of the study.

\section{Data analysis}

Thematic analysis was conducted for the data collected through the interviews. Coding, which was done by two members of the research team, was initially conducted by breaking responses into similar concepts and ideas. Minimal discrepancies were found after cross-checking the work between the two team members. Disagreements were discussed until a consensus was achieved. This was followed by axial coding, which comprised the organisation of the emerging concepts into themes and categories.

\section{Patient and public involvement}

No patients were involved in this study.

\section{RESULTS \\ Survey results \\ General results}

In total, 2694 questionnaires from the 2017 assessment round and 1000 from the 2019 assessment round were completed, giving a response rate of $59.8 \%$ and $22.2 \%$, respectively. However, the response rates in the previous two rounds were $85.7 \%^{14}$ and $57.6 \%,{ }^{4}$ respectively (table 1). The discrepancy in the response rate was observed as we stopped the second data collection in 2019 as the organisation was preparing for the final survey of dual accreditation by both national and international accreditation bodies. We were concerned about the potential biases or false positive responses that might arise during the deep engagement of all of the staff at all levels in these accreditation activities.

Despite the low response rate in 2019 , the study sample size is more than the minimum sample size recommended by the AHRQ. ${ }^{7}$ Moreover, all three previous PSC surveys in 2012, 2015 and 2017 conducted at our institution showed good response rates of $>50 \%(85.7 \%, 57.6 \%$ and $59.8 \%$, respectively). In this study, we reflected and interpreted the four PSC surveys simultaneously.

Most respondents in all four assessment rounds were nurses $(50.1 \%, 78.3 \%, 56 \%$ and $61.7 \%$, respectively). Most respondents were female in the four assessment 
Table 1 Sociodemographic and professional characteristics of the respondents along with the number of events reported and patient safety grades

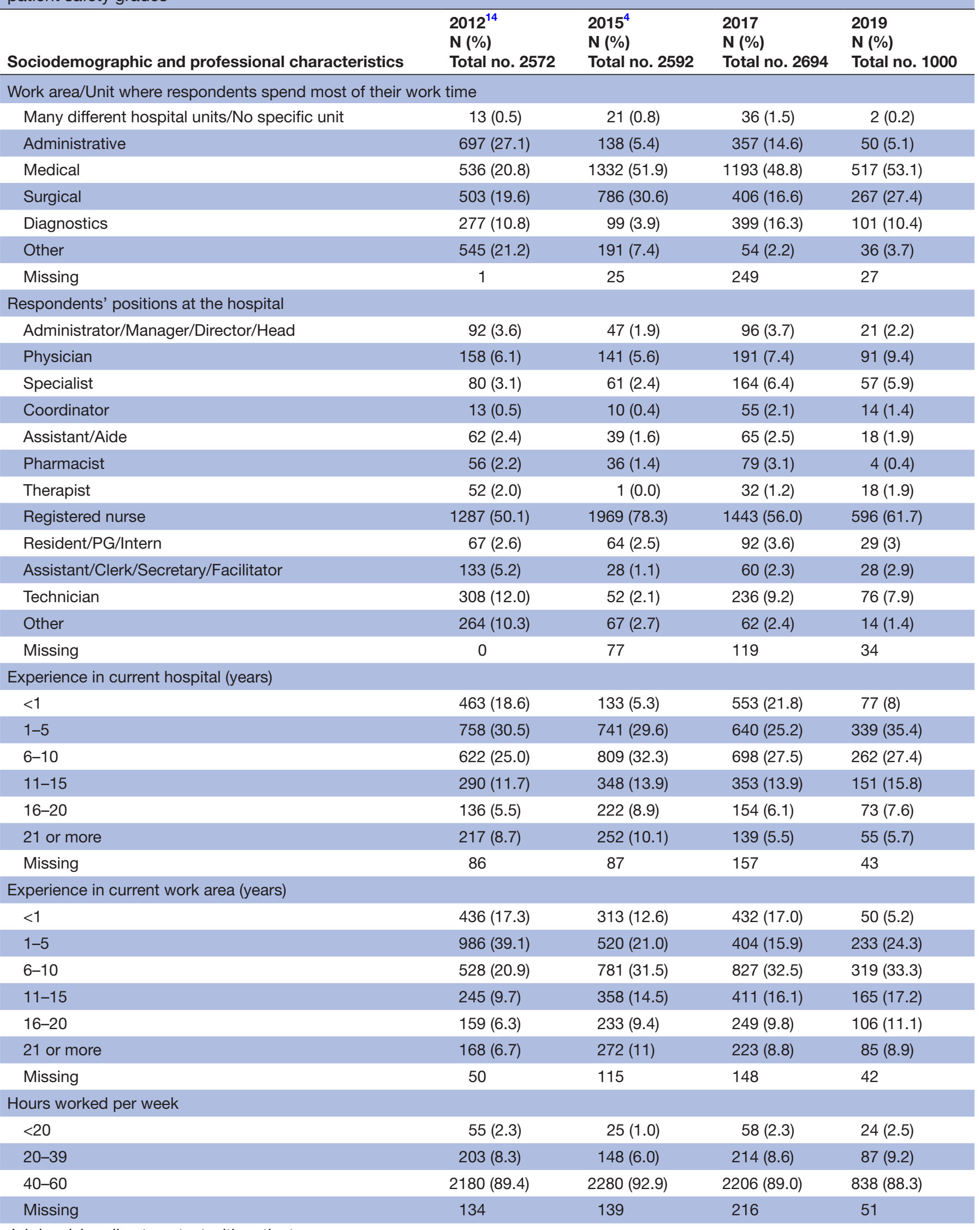

Job involving direct contact with patients 
Table 1 Continued

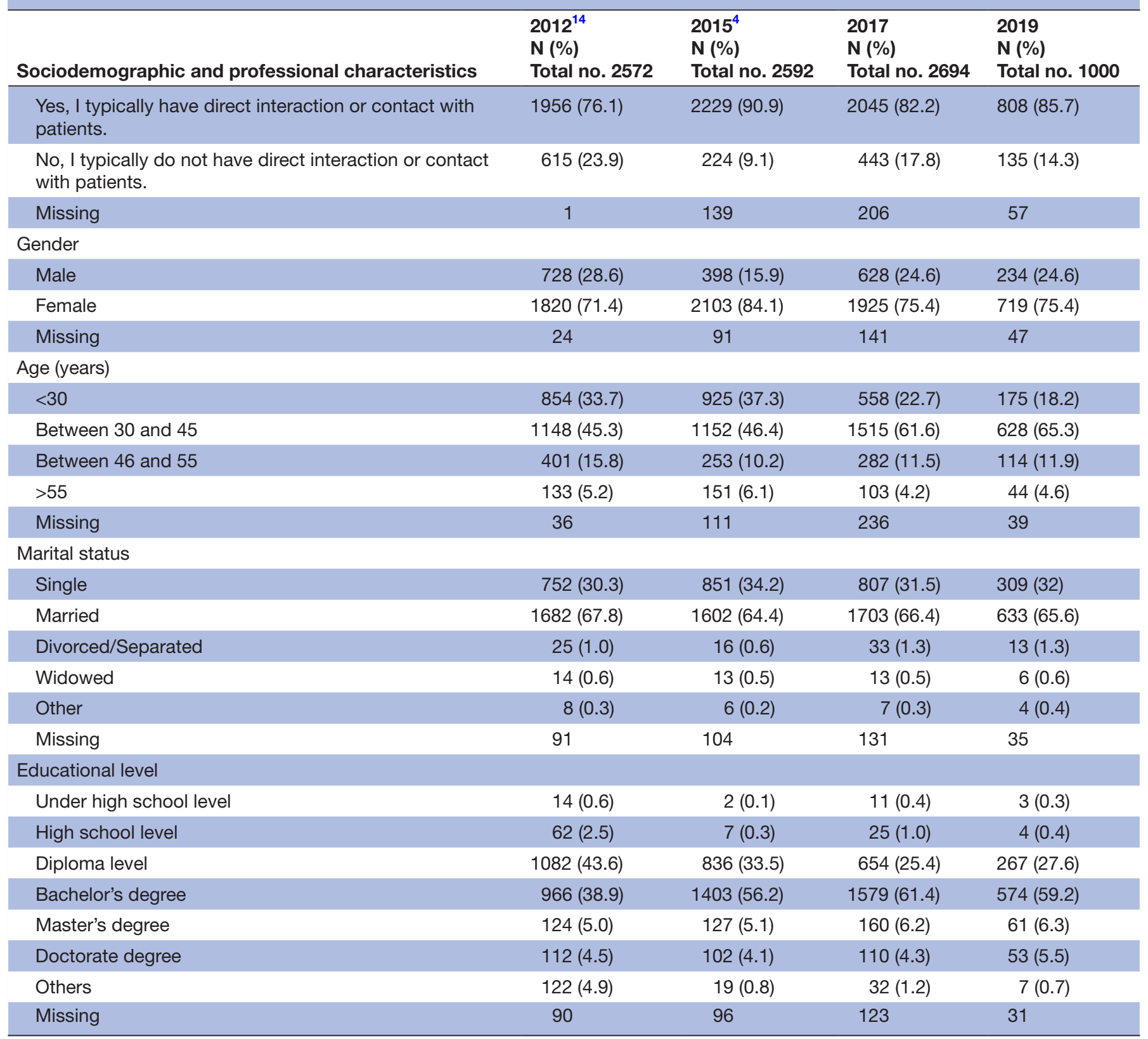

rounds that could be explained by the fact that the approximate proportion of our nursing staff is approximately $27 \%$ of the total number of employees including both clinical and non-clinical staff. Moreover, our nursing staff predominantly comprised females (87\%). Approximately half of the respondents were aged between 30 and 45 years $(45.3 \%, 46.4 \%, 61.6 \%$ and $65.3 \%$ in 2012, 2015 , 2017 and 2019, respectively).

Among the study respondents, the majority held a Bachelor's degree $(38.9 \%, 56.2 \%, 61.4 \%$ and $59.2 \%$ in years 2012, 2015, 2017 and 2019, respectively), whereas $43.6 \%$ in 2012 and $25.4 \%$ in 2017 had diplomas. A large proportion of the respondents in the 2015 and 2017 assessment rounds had 6-10 years of experience in the hospital (32.3\% and $27.5 \%$, respectively), whereas $30.5 \%$ and $35.4 \%$ had $1-5$ years of experience in the hospital in the 2012 and 2019 assessment rounds, respectively. Additionally, approximately half of the staff reported working in medical units in all assessment rounds, except in 2012 , where $27.1 \%$ of the respondents were working in the hospital administration. Moreover, $>75 \%$ of the personnel had been in direct contact with patients and working 40-60 hours a week in all four assessment surveys.

PSC dimensions

PSC dimensions were examined (table 2). The dimensions with the highest average response rates, considered areas of strength, were 'organisational learning-continuous improvement' ranging from $79.6 \%$ to $83.9 \%$ between 2012 and 2019 and 'teamwork within units' that scored $>75 \%$ in all four assessments. Furthermore, the average response rates of the 'hospital management support for 
Table 2 Distribution of positive responses in the survey dimensions

\begin{tabular}{|c|c|c|c|c|}
\hline Patient safety culture dimensions & 2012 & 2015 & 2017 & 2019 \\
\hline Teamwork within units & $78.5 \%$ & $84.8 \%$ & $81.6 \%$ & $84.5 \%$ \\
\hline Supervisor/Manager expectations and actions promoting patient safety & $60.6 \%$ & $60.8 \%$ & $60.4 \%$ & $64.0 \%$ \\
\hline Management support for patient safety & $70.4 \%$ & $75.3 \%$ & $73.3 \%$ & $73.8 \%$ \\
\hline Overall perceptions of patient safety & $65.3 \%$ & $59.5 \%$ & $59.6 \%$ & $61.7 \%$ \\
\hline Communication openness & $42.9 \%$ & $45.0 \%$ & $48.5 \%$ & $49.8 \%$ \\
\hline Frequency of events reported & $59.4 \%$ & $68.8 \%$ & $64.9 \%$ & $66.6 \%$ \\
\hline Teamwork across units & $61.6 \%$ & $67.0 \%$ & $64.1 \%$ & $65.8 \%$ \\
\hline Staffing & $35.1 \%$ & $33.8 \%$ & $30.8 \%$ & $31.9 \%$ \\
\hline Handoffs and transitions & $51.5 \%$ & $55.8 \%$ & $49.6 \%$ & $52.2 \%$ \\
\hline
\end{tabular}

patient safety' dimension were $70.4 \%, 75.3 \%, 73.3 \%$ and $73.8 \%$ in 2012, 2015, 2017 and 2019, respectively.

All surveys had the same areas requiring improvement. There is a general trend towards improvement in per cent positive scores from 2012 to 2019, except for the 'frequency of events reported' composite. Note that 'overall perception of patient safety' was found to be an area for improvement in 2012; however, it was shown to be an area of strength in 2019. The lowest reported average percentage was below $30 \%$ for 'non-punitive response to error' throughout the four assessment rounds. Additionally, staffing and communication openness were the next lowest-scoring composites across the four assessment rounds (table 2 ).

Comparing the results from 2012 with those of 2019

The Kruskal-Wallis test was conducted to compare the results from all four surveys (table 3). As a result,

Table 3 The Kruskal-Wallis test comparing the composite scores in 2012 with those in 2019

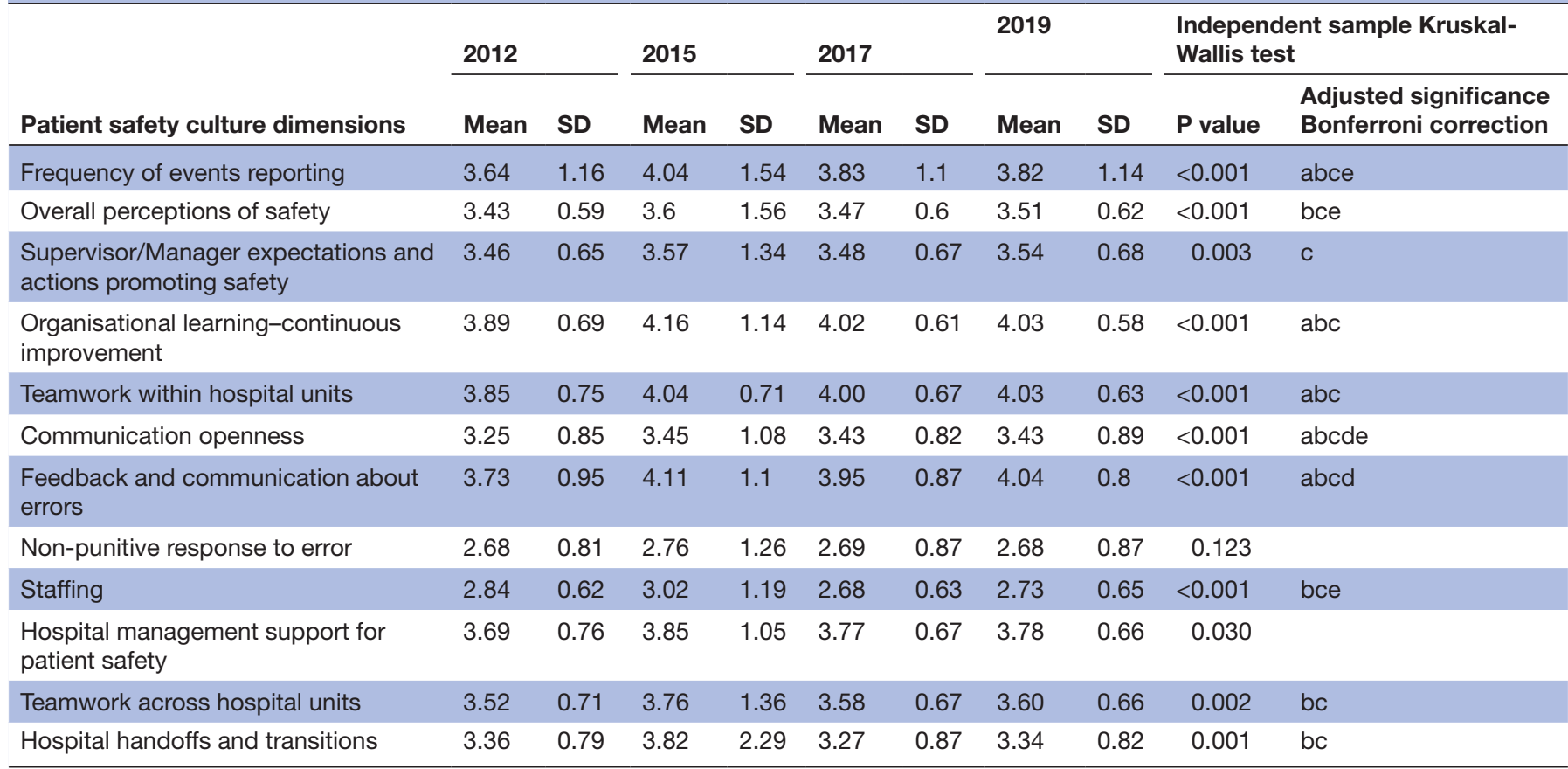

Letter indicates a p-value $<0.05$ adjusted significance using the Bonferroni correction for multiple tests:

a 2012-2017

b 2012-2019

c 2012-2015

d 2017-2019

e 2017-2015

f 2019-2015 
Table 4 Chi-squared test comparing patient safety grades and the number of events reported between 2012 and 2019

\begin{tabular}{|c|c|c|c|c|c|}
\hline Patient safety grade & $\begin{array}{l}2012 \\
\text { N (\%) }\end{array}$ & $\begin{array}{l}2015 \\
\text { N (\%) }\end{array}$ & $\begin{array}{l}2017 \\
\text { N (\%) }\end{array}$ & $\begin{array}{l}2019 \\
\text { N (\%) }\end{array}$ & $P$ value \\
\hline Poor/Failing & $119(4.8 \%)$ & $57(2.3 \%)$ & $67(2.6 \%)$ & $18(1.9 \%)$ & $<0.001$ \\
\hline Excellent/Very good & $1714(69.5)$ & $1747(71.1 \%)$ & $1859(73.2 \%)$ & $710(74.1 \%)$ & \\
\hline \multicolumn{6}{|c|}{ Number of events reported } \\
\hline$>5$ event reports & $154(6.4 \%)$ & $141(5.8 \%)$ & $223(8.9 \%)$ & $75(8 \%)$ & \\
\hline
\end{tabular}

significant differences lie across the four surveys with the exception to the 'supervisor/manager expectations and actions promoting patient safety' and 'non-punitive response to error' composites. A comparison of the mean scores between 2012 and 2019 showed a steady increase in composite scores. The statistical significance of these differences varied according to the survey composites; however, it is worth noting that the highest scores were observed in 2015.

'Non-punitive response to error' and 'staffing' remained the lowest-scoring composites in all assessment rounds, but the difference is not statistically significant. The highest-ranking composite for all surveys was 'organisational learning-continuous improvement'.

\section{Patient safety grade and event reporting}

The percentage of the respondents who evaluated patient safety in their work area/unit as excellent/very good increased from $69.5 \%$ in 2012 to $74.1 \%$ in 2019 ( $\mathrm{p}<0.001)$ (table 4). Moreover, table 4 displays the percentages of the number of events reported; the analysis indicated that the percentages of the respondents who reported no events in the last 12 months decreased by almost 7.4\% from 2012 to $2019(\mathrm{p}<0.001)$ and the percentages of reporting more than five event reports increased from $6.4 \%$ in 2012 to $8 \%$ in 2019 .

\section{Interview results}

\section{Characteristics of the respondents}

In total, 91 healthcare professionals were interviewed, among whom 10 were executive leaders (corporate level), 8 were hospital directors and 13 were departmental chairpersons and directors. The researcher conducted interviews with four focus groups consisting of 60 frontliner staff. Most of the staff in the focus groups comprised physicians, pharmacists, nurses and allied health technicians. The qualitative data obtained from the interviews were thematically categorised into the following: realising changes in PSC in the facility/ departments, factors influencing the PSC in healthcare, barriers to establishing PSC and how to overcome them and suggestions to improve patient safety (see online supplemental table 2S).

\section{Changes in PSC in the facility}

The interviews showed that the respondents believe that the PSC in their department has changed. Some of the documented observed changes included changes in the overall culture, more awareness among the staff, improved communication, increased error reporting, improved understanding and following hospital policies and procedures, improved care processes within the hospital, provision of guides and manuals, more awareness of the risks and how to avert them and addressing staff fears about the punitive culture.

Some factors reported by the respondents that may have contributed to these changes include the multiple accreditation surveys and the introduction of an electronic event reporting system. Despite the learning curve associated with both interventions, the respondents reported that it has allowed them to streamline their operations, enabled them to provide quality care to patients and improved the process of error reporting.

The respondents indicated that the main changes they saw in their department was the amendment of existing policies and procedures, the clarification of job descriptions and roles and making the staff less resistant to change. In addition, hospital leadership observed better communication and teamwork across the hospital and better staff awareness on the topic.

\section{Factors influencing PSC in healthcare}

According to the hospital leaders, making patients at the core of the PSC is the first step in the right direction. This requires support at the leadership and administration levels. Hospital leaders reported that accreditation was one of the factors that changed the culture within their organisation. It has improved communication between the staff and patients and within and across departments, staff training (including continuing education and training) and teamwork within and across units, particularly regarding handoffs and transitions. These were all considered factors that could support and improve event reporting and eventually lead to performance improvement.

Some of the factors that may influence PSC reported by the respondents included leadership and administrative 
support, monitoring and evaluation (including feedback) of patient safety indicators, the number of staff available, improvement of the error reporting system, receiving feedback on reported events, clarity and correct implementation of policies and procedures, implementing a system for monitoring patient safety goals and improving workflow within specific departments. Some respondents reported that all hospital staff is responsible for improving the PSC, whereas other respondents placed the responsibility solely on the leaders and managers.

\section{Barriers to establishing PSC and how to overcome them}

Some of the documented barriers to establishing a PSC included poor communication within and across departments, punitive culture, limited staff awareness, staff resistance to change, staff shortages, language barrier, limited cooperation from physicians and poor training of staff. Other less frequently mentioned barriers included staffing, budget and space.

\section{Organisational changes since 2012}

The slight dip in the composite scores in 2017 could be attributed to several organisation-wide factors that occurred during this transition period. Introducing new human resources regulations and workflows during the shift from the traditional civil service to a self-operation system, a national trend throughout the Kingdom, had a significant impact on recruitment, recontracting and staff retention and turnover.

Another factor was the preparation for the dual accreditation (ie, national and international) final surveys that were scheduled in December 2017 had several positive and negative implications. Overwhelming the staff with changes and escalations of improvement during a short period were among the negative effects.

The outset of 2017 witnessed the separation of the administration of the university hospitals (healthcare) quality from the academic (medical education) quality. Widespread expansions throughout the organisation occurred including the opening of a new large eastern building that added to the total bed capacity of the hospital, increasing from 948 in 2014 to 1160 in 2019. This added bed capacity had an additional burden to all categories of healthcare providers, especially physicians and nurses. The launching of new innovative healthcare services such as oncology, nuclear medicine and radiotherapy, home care and genetics and metabolic and the addition of the new workflows, dynamics and policies into the existing setting posed an additional burden to specialised expert healthcare providers.

Other organisational initiatives include conducting regular 'quality days' to share experiences and recognise and reward distinguished contributions of staff and departments.

Several strategies were initiated to enhance the communication between top management and the frontline staff to identify and discuss facilitators and barriers, including an 'open day', 'patient safety leadership walk-rounds' and 'breakfast with the chief executive officer'.

An occurrence variance reporting (OVR) system was launched as a paper-based system in 2010 , followed by the first round of PSC survey in $2012^{14}$ that inspired the organisation to gradually improve the OVR system through its digitalisation in 2013 with multiple functionalities such as anonymous reporting and reporting feedback. ${ }^{22}$

\section{Suggestions to improve patient safety}

The respondents believed that increasing staffing; offering rewards to staff demonstrating excellence in performance; providing more training and education to staff, managers and leaders and improving communications and teamwork within and across departments will improve patient safety. Implementing a horizontal chain of command, more support from the management and leadership, giving feedback on events reported so that staff can see tangible results from their efforts, and supporting a non-punitive culture are important factors in enhancing the PSC in the organisation. Some respondents indicated that some ways that managers can improve patient safety include using an open-door leadership approach, rewarding and empowering staff demonstrating initiative and excellence in patient safety and using walk-rounds as a way to show the leaders' commitment to engaging with the staff.

In addition, the leaders proposed continuing education and training to staff in addition to regular meetings to discuss quality and patient safety as this would encourage more reporting. Additional ways to improve the PSC in the organisation included increasing the space and number of machines available to decrease waiting time and accommodate urgent cases.

Some suggestions proposed by the interviewees for improving patient safety included better management of patient flow to avoid crowding and reduce waiting time, better triage and patient assessment, better implementation of policies and procedures and improved infrastructure. In addition, supporting departmental initiatives relating to patient safety and disseminating the results of those initiatives, and empowering the staff to obtain their commitment can enhance patient safety.

Other suggestions included brainstorming sessions for the staff, initiating projects spearheaded by the departments to improve patient safety and hosting a 'quality day' particularly targeting newly recruited staff, and hosting huddles within departments to identify areas for improvement. In addition, more suggestions included empowering the quality committee, creating ambassadors in the hospital supported by the hospital leadership and making the work and impact of these ambassadors more visible.

\section{DISCUSSION AND CONCLUSIONS}

This is the first study to progressively document results of a survey on PSC in four consecutive rounds, particularly in Saudi Arabia. The findings of this study can inform 
hospital leaders on the changes in performance as a result of quality improvement plans and accreditation.

The study revealed a general positive trend in scores as we compare results from 2012 to 2019. A spike in the scores was observed in 2015, and this was attributed to the accreditation survey conducted that year and the corresponding leadership visibility and support during that time. The introduction of an OVR system further reinforced the organisational shift in culture towards one that was centred on creating system changes valuing patient safety.

At the regional level, many scholars have evaluated PSC in different settings. Similar to our results, their findings showed that the areas of strength were 'teamwork within units' and 'organisational learning-continuous improvement'. Alternatively, the areas for improvement were 'promoting non-punitive response to error', 'encouraging the openness of communication among healthcare professionals' and 'facilitating hospital handoffs and transition process'. ${ }^{4} 171823-25$ At the international level, similar areas for improvement were identified in hospitals. ${ }^{26-28}$

We observed a persistent discrepancy between the results of the outcome measures 'frequency of events reported' and 'non-punitive response to errors' throughout the four PSC surveys, despite the high reported average percentage of 'feedback and communication about errors'. This may reflect the residual internal conflict that the hospital staff have between their desire to report errors on one hand and the predominant culture of blame on the other hand.

A further gap was noticed as management support for patient safety had one of the highest proportions of positive responses, but non-punitive response to error had one of the lowest percentages of positive responses. A possible explanation for this would be that the low proportion of positive non-punitive response to error was related to the fact that approximately half the responses indicated that no events had been reported (table 4). Moreover, communicating about and addressing safety issues between healthcare leaders and frontliners and developing training programmes to help them understand their roles in the development of PSC could fill this gap. $^{29}$

Accreditation in itself is a major undertaking for hospitals that subjects the hospital to a learning curve for which the major benefits are gained in the first three years with decreasing perceived challenges after 10 years. ${ }^{30}$ Hospitals can and should leverage on accreditation as a stepping stone to achieve organisation-wide improvement in practice and patient outcomes. As demonstrated in the study results, steady improvements were observed with time, and while results appeared to have stabilised, the gained benefits extended beyond the mere numbers to a wider and more tangible organisational change in culture and staff perceptions.

Clearly, the aforementioned organisational changes led to tangible results in the overall PSC. A culture assessment in itself raises staff awareness, promotes a safe patient environment and helps the hospital establish a common vocabulary and shared goals. ${ }^{8}$ Teamwork within and across units, organisational learning, managerial support, overall perception of safety and feedback and communication about error consistently were areas of strength. This reflects and reinforces hospital commitment to address areas supporting improvement of the overall culture of safety. ${ }^{414}$

Despite some improvements, it is of note that nonpunitive response to error, staffing and communication and openness consistently remain the lowest-scoring composites. ${ }^{4} 14$ Non-punitive response to error gives hospital staff the confidence to report without fear of punishment and is critical for the hospital to collect data on system deficiencies. ${ }^{31}$ Suboptimal staffing is potentially the most critical challenge in ensuring patient safety as overworked staff can suffer from lapses in performance. $^{32-35}$ Poor communication in healthcare can lead to avoidable outcomes compromising patient care quality. ${ }^{36}$ Clearly, the hospital should address challenges on these composites as they have an undeniable impact on patient care outcomes. ${ }^{37}$

With this in mind, building a stronger culture requires committed and willing hospital leaders engaged in strategies that strengthen the systems governing the organisational culture. ${ }^{38}{ }^{39}$ Strong leaders view adverse errors as opportunities for learning and system improvement, ${ }^{40} 41$ which would ultimately build a more solid foundation for safety. A shared organisational culture fostering safety is built around a foundation of shared decision making, leadership commitment, mutual trust and opportunities for learning and growth. ${ }^{42}$ Collectively, these comprise some traits making an organisation more adaptable and receptive to addressing emerging challenges. ${ }^{38}$ Hospital leaders should collectively address challenges such as poor communication, lack of visible leadership, poor teamwork, lack of reporting systems, inadequate analysis of adverse events and inadequate staff knowledge about safety. ${ }^{24}$

A consistent improvement in PSC requires maintaining the improvements achieved so far. Patient safety is a moving target and failing to consistently address the areas for improvement at the hospital-wide level will not allow the hospital to maintain the gains achieved to date. Leadership commitment is more important than ever to consistently and visibly support PSC. The study results confirm that quality improvement initiatives can lead to visible changes in the hospital culture and that consistent managerial support can help the hospital in maintaining these improvements. Hospital leaders and managers can leverage on organisational changes to make lasting changes to the system and create a spillover effect on the entire healthcare team. Navigating these changes meticulously will allow hospital leaders to sow the seeds of change and maintain the gains of the implemented interventions (box 1). 
Box 1 Strategies or interventions to promote

improvements in patient safety

- Leveraging on accreditation as a stepping stone to achieve organisation-wide improvement in practice and patient outcomes.

- Leadership engagement, support and commitment governing the organisational culture.

- Sharing and viewing adverse errors as opportunities for learning and system improvement and offering regular feedback on reported events.

- Shared decision making, mutual trust and identifying opportunities for learning and growth.

- Launching and maintaining quality improvement initiatives.

- Improving the human resources regulations, workflows and staffing.

- Empowering the quality management department through having direct liaison and representation in all executive boards and committees.

- Investing in the infrastructure of the organisation to meet patient safety standards and goals.

- Conducting regular quality activities (eg, 'quality days') to communicate and exchange experiences and success stories, and recognising improvement achievements throughout the organisation.

- Enhancing communication between the top management and frontline staff by conducting regular activities like 'patient safety leadership walk-rounds', 'open day with the executives' and 'breakfast with the executives'.

- Digitalising the health information system and the incident reporting system.

- Providing continuous training and education.

- Improving communications and teamwork within and across departments (eg, multidisciplinary meetings, focus group discussions and information and communication technology utilisation).

- Developing a clear policy, training and workflow involving all managerial levels to support a just culture.

- Enhancing the patient flow process through establishing a unit solely working on patient flow and case management.

\section{Strengths and limitations}

The strengths of our study include using a mixed-methods design to assess PSC progressively in four consecutive rounds in Saudi Arabia over a period of eight years. It provides us with insight on key areas for improving PSC and persistent challenges in healthcare organisations.

Conducting this study in a tertiary care teaching multisite hospital may not fully reflect patient safety culture in Saudi Arabia. Despite the low response rate in 2019, the study sample size is more than the minimum sample size recommended by the AHRQ. Moreover, we used the mixed-methods design to minimise the occurrence of spurious correlations due to the commonmethod variance that is often inherent in any survey instrument.

\section{Implications for patient safety research}

Further patient safety research is needed as there is a shortage in the literature understanding how hospital safety culture impacts patient and worker safety outcomes. Repeated assessments of patient safety culture can provide unparalleled insight for hospital leaders into organisational changes resulting from quality improvement initiatives. Future research should link the results of patient safety culture assessments with patient, worker and health system outcomes.

\section{Author affiliations}

${ }^{1}$ Quality Management, King Saud University Medical City, Riyadh, Riyadh Province, Saudi Arabia

${ }^{2}$ Research Chair for Evidence Based Health Care and Knowledge Translation, King Saud University Medical City, Riyadh, Riyadh Province, Saudi Arabia

${ }^{3}$ Surgery, King Saud University College of Medicine, Riyadh, Riyadh Province, Saudi Arabia

${ }^{4}$ Pediatrics, King Saud University Medical City, Riyadh, Saudi Arabia

${ }^{5}$ Health Management and Policy, American University of Beirut Faculty of Health Sciences, Beirut, Lebanon

${ }^{6}$ Health Research Methods, Evidence, and Impact, McMaster University, Hamilton, Ontario, Canada

Correction notice This article has been corrected since it was first published. The article title has been corrected.

Twitter Yasser S Amer @yassersamiamer2

Acknowledgements The authors would like to thank the department chairmen and directors, healthcare providers, managers and executives who participated in our study. The authors would also like to thank the quality management coordinators for their participation in the data collection, namely, Mariam Napuli and Estrelita Dela Cruz. This study was supported by King Saud University, Deanship of Scientific Research, Research Chair for Evidence-Based Health Care and Knowledge Translation, Riyadh, Saudi Arabia. Furthermore, we would like to extend our thanks to the Researchers Support \& Services Unit at King Saud University for technical support and the King Saud University Medical City for logistics and resources.

Contributors MAT contributed to the study design, writing of the first draft of the manuscript and review. MAT, MMB, BZ and RAMA contributed to data collection and review. FAA and YSA critically reviewed the manuscript for important intellectual content. DJ contributed to data analysis and review. FE-J contributed to study design, data analysis, manuscript development and review. All authors read and approved the final version of the manuscript.

Funding This work was supported by the Research Chair for Evidence-Based Health Care and Knowledge Translation, Deanship of Scientific Research, King Saud University, Riyadh, Saudi Arabia.

Competing interests None declared.

Patient consent for publication Not required.

Ethics approval The study protocol and instruments were reviewed and approved (no. E19-4315) by the institutional review board (IRB) of the King Saud University College of Medicine.

Provenance and peer review Not commissioned; externally peer reviewed.

Data availability statement All data relevant to the study are included in the article or uploaded as supplementary information. All relevant data were made available as tables and figures in this article and other previously published articles.

Supplemental material This content has been supplied by the author(s). It has not been vetted by BMJ Publishing Group Limited (BMJ) and may not have been peer-reviewed. Any opinions or recommendations discussed are solely those of the author(s) and are not endorsed by BMJ. BMJ disclaims all liability and responsibility arising from any reliance placed on the content. Where the content includes any translated material, BMJ does not warrant the accuracy and reliability of the translations (including but not limited to local regulations, clinical guidelines, terminology, drug names and drug dosages), and is not responsible for any error and/or omissions arising from translation and adaptation or otherwise.

Open access This is an open access article distributed in accordance with the Creative Commons Attribution Non Commercial (CC BY-NC 4.0) license, which permits others to distribute, remix, adapt, build upon this work non-commercially, and license their derivative works on different terms, provided the original work is properly cited, appropriate credit is given, any changes made indicated, and the use is non-commercial. See: http://creativecommons.org/licenses/by-nc/4.0/.

\section{ORCID iDs}

Maher Abdelraheim Titi http://orcid.org/0000-0003-1079-4118

Yasser S Amer http://orcid.org/0000-0003-4097-2317 


\section{REFERENCES}

1 Kellogg KM, Hettinger Z, Shah M, et al. Our current approach to root cause analysis: is it contributing to our failure to improve patient safety? BMJ Qual Saf 2017;26:381-7.

2 Bates DW, Singh $\mathrm{H}$. Two decades since to err is human: an assessment of progress and emerging priorities in patient safety. Health Aff 2018;37:1736-43.

3 Organization WH. Patient safety: making health care safer. World Health Organization, 2017.

4 Alswat K, Abdalla RAM, Titi MA, et al. Improving patient safety culture in Saudi Arabia (2012-2015): Trending, improvement and benchmarking. BMC Health Serv Res 2017;17:516.

5 Neto AV, Silva MD, De Medeiros SG. Patient safety culture in health organizations: Scoping review. International Archives of Medicine 2017;10.

6 Elmontsri M, Almashrafi A, Banarsee R, et al. Status of patient safety culture in Arab countries: a systematic review. BMJ Open 2017;7:e013487.

7 Sorra JGL, Streagle S, et al. AHRQ Hospital Survey on Patient Safety Culture: User's Guide.: (Prepared by Westat, under Contract No. HHSA290201300003C). AHRQ Publication No. 15-0049-EF (Replaces 04-0041. Rockville, MD: Agency for Healthcare Research and Quality, 2016.

8 Nieva VF, Sorra J. Safety culture assessment: a tool for improving patient safety in healthcare organizations. Qual Saf Health Care 2003;12 Suppl 2:17ii-23.

9 Gershon RRM, Stone PW, Bakken S, et al. Measurement of organizational culture and climate in healthcare. J Nurs Adm 2004;34:33-40

10 Gutberg J, Berta W. Understanding middle managers' influence in implementing patient safety culture. BMC Health Serv Res 2017;17:1-10.

11 Sine DM, Northcutt N. Interactive qualitative assessment of patient safety culture survey scores. J Patient Saf 2008;4:78-83.

12 Kirk S, Parker D, Claridge T, et al. Patient safety culture in primary care: developing a theoretical framework for practical use. Qual Saf Health Care 2007;16:313-20.

13 Hodgen A, Ellis L, Churruca K. Safety culture assessment in health care: a review of the literature on safety culture assessment modes. Sydney: Australian Commission on Safety and Quality in Health Care 2017.

14 El-Jardali F, Sheikh F, Garcia NA, et al. Patient safety culture in a large teaching hospital in Riyadh: baseline assessment, comparative analysis and opportunities for improvement. BMC Health Serv Res 2014; $14: 122$

15 Sorra JS, Dyer N. Multilevel psychometric properties of the AHRQ Hospital survey on patient safety culture. BMC Health Serv Res 2010;10:199.

16 Alsalem G, Bowie P, Morrison J. Assessing safety climate in acute hospital settings: a systematic review of the adequacy of the psychometric properties of survey measurement tools. BMC Health Serv Res 2018:18:353.

17 El-Jardali F, Jaafar M, Dimassi H, et al. The current state of patient safety culture in Lebanese hospitals: a study at baseline. Int J Qual Health Care 2010;22:386-95.

18 Khater WA, Akhu-Zaheya LM, Al-Mahasneh SI, et al. Nurses' perceptions of patient safety culture in Jordanian hospitals. Int Nurs Rev 2015;62:82-91.

19 Wami SD, Demssie AF, Wassie MM, et al. Patient safety culture and associated factors: a quantitative and qualitative study of healthcare workers' view in Jimma zone hospitals, Southwest Ethiopia. BMC Health Serv Res 2016;16:495.

20 Liu C, Liu W, Wang Y, et al. Patient safety culture in China: a case study in an outpatient setting in Beijing. BMJ Qual Saf 2014;23:556-64.
21 Listyowardojo TA, Yan X, Leyshon S, et al. A safety culture assessment by mixed methods at a public maternity and infant hospital in China. J Multidiscip Healthc 2017;10:253-62.

22 Abu Alrub AM AY, Titi MA, ACA M, et al. Barriers and enablers in implementing an electronic incident reporting system in a teaching hospital: a case study from Saudi Arabia. Manuscript submitted for publication 2019.

23 Alahmadi HA. Assessment of patient safety culture in Saudi Arabian hospitals. Qual Saf Health Care 2010;19:e17.

24 Ammouri AA, Tailakh AK, Muliira JK, et al. Patient safety culture among nurses. Int Nurs Rev 2015;62:102-10.

25 Badr HE, AlFadalah T, El-Jardali F. Towards promoting patient safety practices: baseline assessment of patient safety culture in three private hospitals. Int J Healthc Manag 2017:1-8.

26 Famolaro T, Yount ND, Burns W. Hospital survey on patient safety culture: 2018 user comparative database report: agency for healthcare research and quality 2018

27 Okuyama JHH, Galvao TF, Silva MT. Healthcare professional's perception of patient safety measured by the hospital survey on patient safety culture: a systematic review and meta-analysis. ScientificWorldJournal 2018;2018:1-11.

28 Nie $\mathrm{Y}, \mathrm{Mao} X, \mathrm{Cui} \mathrm{H}$, et al. Hospital survey on patient safety culture in China. BMC Health Serv Res 2013;13:228.

29 Quenon J-L, Vacher A, Faget M, et al. Exploring the role of managers in the development of a safety culture in seven French healthcare facilities: a qualitative study. BMC Health Serv Res 2020;20:1-11.

30 Pomey M-P, Lemieux-Charles L, Champagne F, et al. Does accreditation stimulate change? A study of the impact of the accreditation process on Canadian healthcare organizations. Implement Sci 2010;5:31.

31 Smits M, Wagner C, Spreeuwenberg P, et al. Measuring patient safety culture: an assessment of the clustering of responses at unit level and hospital level. Qual Saf Health Care 2009;18:292-6.

32 Sanders J, Cook G. Abc of patient safety. Blackwell: Oxford, 2007.

33 Baldwin DC, Daugherty SR, Tsai R, et al. A national survey of residents' self-reported work hours: thinking beyond specialty. Acad Med 2003;78:1154-63.

34 Aiken LH, Sloane DM, Bruyneel L, et al. Nurse staffing and education and hospital mortality in nine European countries: a retrospective observational study. Lancet 2014;383:1824-30.

35 Sturm H, Rieger MA, Martus $\mathrm{P}$, et al. Do perceived working conditions and patient safety culture correlate with objective workload and patient outcomes: a cross-sectional explorative study from a German university hospital. PLoS One 2019;14:e0209487.

36 Vermeir P, Vandijck D, Degroote S, et al. Communication in healthcare: a narrative review of the literature and practical recommendations. Int J Clin Pract 2015;69:1257-67.

37 Lee SE, Scott LD, Dahinten VS, et al. Safety culture, patient safety, and quality of care outcomes: a literature review. West J Nurs Res 2019;41:279-304.

38 Chassin MR, Loeb JM. High-reliability health care: getting there from here. Milbank Q 2013;91:459-90.

39 Smetzer J, Baker C, Byrne FD, et al. Shaping systems for better behavioral choices: lessons learned from a fatal medication error. $J t$ Comm J Qual Patient Saf 2010;36:152-AP2.

40 Clarke JR, Lerner JC, Marella W. The role for leaders of health care organizations in patient safety. Am J Med Qual 2007;22:311-8.

41 Parand A, Dopson S, Vincent C. The role of chief executive officers in a quality improvement : a qualitative study. BMJ Open 2013;3. doi:10.1136/bmjopen-2012-001731. [Epub ahead of print: 03 Jan 2013].

42 Blignaut AJ, Coetzee SK, Klopper HC. Nurse qualifications and perceptions of patient safety and quality of care in South Africa. Nurs Health Sci 2014;16:224-31. 